\title{
The impact of nurse working hours on patient safety culture: a cross-national survey including Japan, the United States and Chinese Taiwan using the Hospital Survey on Patient Safety Culture
}

Yinghui Wu' ${ }^{1}$, Shigeru Fujita ${ }^{1}$, Kanako Seto ${ }^{1}$, Shinya Ito ${ }^{1}$, Kunichika Matsumoto ${ }^{1}$, Chiu-Chin Huang ${ }^{2}$ and Tomonori Hasegawa ${ }^{*}$

\begin{abstract}
Background: A positive patient safety culture (PSC) is one of the most critical components to improve healthcare quality and safety. The Hospital Survey on Patient Safety Culture (HSOPS), developed by the US Agency for Healthcare Research and Quality, has been used to assess PSC in 31 countries. However, little is known about the impact of nurse working hours on PSC. We hypothesized that long nurse working hours would deteriorate PSC, and that the deterioration patterns would vary between countries. Moreover, the common trends observed in Japan, the US and Chinese Taiwan may be useful to improve PSC in other countries. The purpose of this study was to clarify the impact of long nurse working hours on PSC in Japan, the US, and Chinese Taiwan using HSOPS.

Methods: The HSOPS questionnaire measures 12 sub-dimensions of PSC, with higher scores indicating a more positive PSC. Odds ratios (ORs) were calculated using a generalized linear mixed model to evaluate the impact of working hours on PSC outcome measures (patient safety grade and number of events reported). Tukey's test and Cohen's d values were used to verify the relationships between nurse working hours and the 12 sub-dimensions of PSC.

Results: Nurses working $\geq 60 \mathrm{~h} /$ week in Japan and the US had a significantly lower OR for patient safety grade than those working $<40 \mathrm{~h} /$ week. In the three countries, nurses working $\geq 40 \mathrm{~h} /$ week had a significantly higher OR for the number of events reported. The mean score on 'staffing' was significantly lower in the $\geq 60-h$ group than in the $<40-h$ group in all the three countries. The mean score for 'teamwork within units' was significantly lower in the $\geq 60-h$ group than in the $<40-h$ group in Japan and Chinese Taiwan.
\end{abstract}

Conclusions: Patient safety grade deteriorated and the number of events reported increased with long working hours. Among the 12 sub-dimensions of PSC, long working hours had an impact on 'staffing' and 'teamwork within units' in Japan, the US and Chinese Taiwan.

Keywords: Patient safety, Patient safety culture, Nurse working hours, Adverse events

\footnotetext{
* Correspondence: tommie@med.toho-u.ac.jp

'Division of Health Policy \& Health Service Research, Department of Social Medicine, Toho University School of Medicine, 5-21-16 Omori-Nishi, Ota-ku, Tokyo 143-8540, Japan

Full list of author information is available at the end of the article
} 


\section{Background}

In 1999, the US Institute of Medicine reported that 44,000-98,000 inpatients in US hospitals are estimated to die because of adverse events each year [1]. Another report mentioned that approximately 1.3 million patients are injured by adverse events during their hospitalization each year [2]. Patient safety is of greatest concern throughout the world. A positive patient safety culture is one of the most critical components that could improve quality and safety in healthcare [3].

Patient safety culture (PSC) is defined as 'the product of individual and group values, attitudes, perceptions, competencies and patterns of behaviour that determines the commitment to, and the style and proficiency of, an organization's health and safety management' [4]. The Hospital Survey on Patient Safety Culture (HSOPS), developed by the US Agency for Healthcare Research and Quality (AHRQ), has been used to assess PSC in 31 countries including Japan and Chinese Taiwan (Taiwan) [5-8].

Professional staff nurses are most likely involved in adverse events and an estimated 11 million nurses throughout the world have a critical impact on safety initiatives [9]. Several studies have indicated that long working hours have adverse effects on nurse performance. Linda et al. showed that nurses working $>40 \mathrm{~h} /$ week had an increased chance to make both errors and near misses [10]. Rogers et al. found that the risks of making an error increased significantly when work shifts were $>12 \mathrm{~h}$, or when staff worked for $>40 \mathrm{~h} /$ week [11]. These studies were based on voluntary reports of errors or near misses. As the increase in reported events can be interpreted as deterioration in patient safety as well as an improved PSC, which enables better detection and reporting, it might be difficult to determine the impact of long working hours on patient safety using the number of reports as an indicator. An assessment of PSC might be an alternative method to evaluate the impact of long working hours on patient safety. The impact of long working hours on PSC might vary between countries because PSC cultural differences have been identified among healthcare workers in Japan, Taiwan and the US [8]. We hypothesized that long working hours would deteriorate PSC, and that the deterioration patterns would differ between countries. Moreover, the common trends observed in Japan, the US and Taiwan may be useful to improve PSC in other countries.

The purpose of this study was to clarify the impact of long working hours on PSC in countries with different cultural backgrounds using the nurse PSC databases in Japan, the US and Taiwan.

\section{Methods}

Data sources and study design

We obtained the US and Taiwan HSOPS data from US AHRQ and a research team in Taiwan, respectively. We also conducted a cross-sectional anonymous survey and constructed a Japanese HSOPS database. The characteristics of the participating hospitals in the three countries are shown in our previous study [8]. Only nurse-related data from the above-mentioned databases were used, because they were the target respondents of this study. Incomplete questionnaires, such as surveys with less than an entire section completed, those with fewer than half the total items completed, or those with identical responses to every item, were excluded from our analysis $[5,6]$.

The US data were a 2010 HSOPS database collected from 884 hospitals from January 2006 to June 2009. All hospital staff at 14 hospitals in Japan were asked to complete the Japanese HSOPS from January 2009 to January 2010. The Taiwanese HSOPS was distributed to a part of the hospital staff in 74 hospitals in Taiwan, from July 2007 to August 2008, chosen from all 556 hospitals in Taiwan by stratified sampling with proportional allocation. The details of the data are shown in our previous study [8].

\section{Questionnaire}

HSOPS has 51 questions divided into three parts as follows: background information (seven items), outcome measures of PSC (two items) and sub-dimensions of PSC (42 items). The background information section includes items regarding respondent's primary unit, staff position, working hours per week and years in current specialty. Outcome measures in the PSC section have two items: (a) patient safety grade, which is measured using a fivepoint Likert scale from 'excellent' to 'failing' for rating patient safety in the respondent's workplace; (b) number of events reported by the respondent during the past year. Sub-dimensions of the PSC section include 42 items with a five-point Likert scale of agreement (from 'strongly disagree' to 'strongly agree') or frequency (from 'never' to 'always'). These 42 items are categorized into the following categories: (1) frequency of event reporting, (2) overall perceptions of safety, (3) supervisor/manager expectations and actions promoting safety, (4) organizational learningcontinuous improvement, (5) teamwork within units, (6) communication openness, (7) feedback and communication about errors, (8) nonpunitive response to error, (9) staffing, (10) hospital management support for patient safety, (11) teamwork across hospital units and (12) hospital handoffs and transitions. Among these subdimensions, 'staffing' was defined as the number of staff required to handle the workload and work hours appropriate to provide the best care for patients. 'Teamwork within units' was defined as the level at which staff support one another, treat one another with respect and work together as a team [5].

Internal reliability and construct validity of the questionnaire were verified in previous studies [6-8]. 


\section{Data analyses}

First, the 42 items in the sub-dimensions of PSC were scored on a five-point Likert scale and scores for negatively worded items were reversed. AHRQ recommends using percentages of positive answers for each subdimension, but those calculation methods decrease the amount of information during numerical transformation. Therefore, in this study, responses to each item within the same sub-dimension were summed, and the mean of each PSC sub-dimension was calculated, resulting in a subdimension score of 3-15 points if there were three items in the sub-dimension.

Second, to estimate the effect of working hours on patient safety grade and number of events reported during the past year, the odds ratio (OR) of working hours per week for patient safety grade and number of events reported were calculated using a generalized linear mixed model (GLMM). The ORs showed the possibility to have high patient safety grade, or to have experience of event reporting. The differences between each hospital and years in their current specialty or profession were included in the GLMM as random effects for measuring the effect of working hours on patient safety grade and number of events reported because patient safety grade and number of events reported were affected by working hours, years in their current specialty or profession and the hospitals where the respondents work.

Finally, to measure the effects of working hours on subdimensions of PSC, nurses were divided into three groups by working hours per week ( $<40 \mathrm{~h} ; 40-60 \mathrm{~h} ; \geq 60 \mathrm{~h})$, and we used Tukey's test to verify whether there were differences in each sub-dimension of PSC among different working-hour groups. To confirm whether the difference was substantially meaningful or not, Cohen's $d$ values were used to indicate the effect size for the mean differences in the 12 sub-dimensions among the working-hour groups. Cohen described a $d$ value of 0.2 as being small, 0.5 as medium and 0.8 as large effects [12].

Chi-square tests were used to compare categorical variables. Descriptive statistics, GLMM, Tukey's tests and

Table 1 Respondent characteristics

\begin{tabular}{|c|c|c|c|c|c|c|c|}
\hline & & \multicolumn{2}{|c|}{ Japan } & \multicolumn{2}{|c|}{ U.S. } & \multicolumn{2}{|c|}{ Taiwan } \\
\hline & & $n$ & $\%$ & $n$ & $\%$ & $n$ & $\%$ \\
\hline \multirow[t]{4}{*}{ Working hours per week in this hospital } & $<40 \mathrm{~h}$ & 930 & 23.0 & 61,904 & 58.0 & 936 & 16.4 \\
\hline & $40-60$ & 2,352 & 58.1 & 35,488 & 33.3 & 4,226 & 74.0 \\
\hline & $\geq 60 \mathrm{~h}$ & 217 & 5.4 & 5,656 & 5.3 & 466 & 8.2 \\
\hline & No answer & 548 & 13.5 & 3,662 & 3.4 & 86 & 1.5 \\
\hline \multirow[t]{7}{*}{ Years in current specialty } & $<1$ & 335 & 8.3 & 6,033 & 5.7 & 491 & 8.6 \\
\hline & $1-5$ & 1,329 & 32.8 & 25,339 & 23.7 & 2,355 & 41.2 \\
\hline & $6-10$ & 846 & 20.9 & 17,261 & 16.2 & 1,521 & 26.6 \\
\hline & $11-15$ & 541 & 13.4 & 13,889 & 13.0 & 740 & 13.0 \\
\hline & $16-20$ & 319 & 7.9 & 12,195 & 11.4 & 345 & 6.0 \\
\hline & $\geq 21$ & 535 & 13.2 & 27,704 & 26.0 & 236 & 4.1 \\
\hline & No answer & 142 & 3.5 & 4,289 & 4.0 & 26 & 0.5 \\
\hline \multirow[t]{6}{*}{ Patient Safety Grade } & Excellent & 135 & 3.3 & 22,410 & 21.0 & 214 & 3.7 \\
\hline & Very good & 1,662 & 41.1 & 48,325 & 45.3 & 1,791 & 31.3 \\
\hline & Acceptable & 1,740 & 43.0 & 25,948 & 24.3 & 2,807 & 49.1 \\
\hline & Poor & 282 & 7.0 & 6,147 & 5.8 & 223 & 3.9 \\
\hline & Failing & 36 & 0.9 & 990 & 0.9 & 22 & 0.4 \\
\hline & No answer & 192 & 4.7 & 2,890 & 2.7 & 657 & 11.5 \\
\hline \multirow[t]{7}{*}{ Number of Events Reported (during the past 1 year) } & No event reports & 717 & 17.7 & 31,506 & 29.5 & 2,523 & 44.2 \\
\hline & $1-2$ & 1,759 & 43.5 & 42,401 & 39.7 & 2,159 & 37.8 \\
\hline & $3-5$ & 1,145 & 28.3 & 21,555 & 20.2 & 649 & 11.4 \\
\hline & $6-10$ & 317 & 7.8 & 6,631 & 6.2 & 163 & 2.9 \\
\hline & $11-20$ & 58 & 1.4 & 2,044 & 1.9 & 45 & 0.8 \\
\hline & $\geq 21$ & 17 & 0.4 & 898 & 0.8 & 23 & 0.4 \\
\hline & No answer & 34 & 0.8 & 1,675 & 1.6 & 152 & 2.7 \\
\hline Total & & 4,047 & 100.0 & 106,710 & 100.0 & 5,714 & 100.0 \\
\hline
\end{tabular}


chi-square tests were performed with SPSS Statistics ver. 19.0 (SPSS, Inc., Chicago, IL, USA). Cohen's $d$ values were calculated using the open-source $\mathrm{R}$ software, version 2.12.1.

\section{Ethical concerns}

According to the Ethical Guidelines for Epidemiological Research, which was drawn up by the Japanese Ministry of Health, Labor and Welfare, approval of the ethics committee was not required because this study was an anonymous and self-administered survey with no intervention or mental anguish [13]. The survey was approved in Taiwan by the Institutional Human Subject Ethic Committee of National Chung Cheng University.

\section{Results}

The US 2010 HSOPS database consisted of 337,862 respondents and the response rate was $41.0 \%$. Among respondents, 114,818 (34.0\%) were nurses. After incomplete questionnaires were excluded, 106,710 (37.0\%) nurses were included. In Japan, 8,192 respondents completed questionnaires and the response rate was $66.5 \%$. Among the respondents, 4,255 (52.0\%) were nurses including 4,047 (58.1\%) valid data. In Taiwan, 10,289 hospital staff completed questionnaires, and the response rate was 88.0\%. Among the respondents, 5,773 (56.1\%) were nurses, in which valid data were available for 5,714 (56.3\%).

The respondent's characteristics are shown in Table 1. US nurses were more likely to rate patient safety conditions of their work area as 'excellent' or 'very good' compared with Taiwan $(\mathrm{P}<0.001)$ and Japan $(\mathrm{P}<0.001)$. The proportion of nurses in Taiwan reporting no events during the past year was higher than that in the US $(\mathrm{P}<0.001)$ and Japan $(\mathrm{P}<0.001)$.

The effects of working hours on outcome measures of PSC are shown in Table 2. Compared with nurses working $<40 \mathrm{~h} /$ week, nurses working $\geq 60 \mathrm{~h} /$ week gave patient safety grade a poorer rating (Japan: OR, 0.65; US: OR, 0.82; Taiwan: OR, 0.84) and had more event reporting experiences (Japan: OR, 2.74; US: OR, 1.11; Taiwan: OR, 1.85).

The effects of working hours on each sub-dimension of PSC are shown in Table 3 and the Additional file 1. In regard to 'staffing' and 'teamwork within units', the mean scores of nurses who worked $\geq 60 \mathrm{~h}$ were significantly lower than the mean scores of nurses who worked $<40 \mathrm{~h}$ if the effect size was considered ('staffing'; Japan: $\mathrm{P}<0.001$, $d=0.50$, US: $\mathrm{P}<0.001, d=0.20$, Taiwan: $\mathrm{P}<0.001, d=0.60$, 'teamwork within units'; Japan: $\mathrm{P}=0.02, d=0.27$, US: $\mathrm{P}<0.001, d=0.14$, Taiwan: $\mathrm{P}=0.005, d=0.24$ ).

\section{Discussion}

The results of this study suggest that the long working hours of nurses deteriorated the patient safety grade of
Table 2 Effect of nurse working hours on patient safety grade and number of adverse events reported

\begin{tabular}{|c|c|c|c|c|}
\hline & Working hours per week & $P$ value & Odds ratio & $95 \% \mathrm{Cl}$ \\
\hline \multicolumn{5}{|c|}{ Patient safety grade } \\
\hline \multirow[t]{3}{*}{ Japan } & $<40$ & & 1.00 & \\
\hline & $40-60$ & 0.31 & 0.92 & $0.78-1.08$ \\
\hline & $\geq 60$ & $0.01^{*}$ & 0.65 & $0.46-0.90$ \\
\hline \multirow[t]{3}{*}{ U.S. } & $<40$ & & 1.00 & \\
\hline & $40-60$ & 0.11 & 1.03 & $0.99-1.06$ \\
\hline & $\geq 60$ & $<0.001^{* *}$ & 0.82 & $0.78-0.88$ \\
\hline \multirow[t]{3}{*}{ Taiwan } & $<40$ & & 1.00 & \\
\hline & $40-60$ & 0.47 & 1.06 & $0.90-1.26$ \\
\hline & $\geq 60$ & 0.18 & 0.84 & $0.64-1.09$ \\
\hline \multicolumn{5}{|c|}{ Number of events reported } \\
\hline \multirow[t]{3}{*}{ Japan } & $<40$ & & 1.00 & \\
\hline & $40-60$ & $<0.001^{* *}$ & 1.72 & $1.41-2.09$ \\
\hline & $\geq 60$ & $<0.001^{* *}$ & 2.74 & $1.68-4.47$ \\
\hline \multirow[t]{3}{*}{ U.S. } & $<40$ & & 1.00 & \\
\hline & $40-60$ & $<0.001^{* *}$ & 1.08 & $1.05-1.11$ \\
\hline & $\geq 60$ & $0.002^{* *}$ & 1.11 & $1.04-1.18$ \\
\hline \multirow[t]{3}{*}{ Taiwan } & $<40$ & & 1.00 & \\
\hline & $40-60$ & $0.009^{* *}$ & 1.23 & $1.05-1.43$ \\
\hline & $\geq 60$ & $<0.001^{* *}$ & 1.85 & $1.45-2.36$ \\
\hline
\end{tabular}

${ }^{*} \mathrm{P}<0.05,{ }^{* *} \mathrm{P}<0.01 ; \mathrm{Cl}$, confidence interval.

their work area and increased the number of nurses with event reporting experience in the three countries. The ratings for 'staffing' and 'teamwork within units' deteriorated as a result of long working hours.

In the US, more than half of nurses worked $<40 \mathrm{~h} /$ week in contrast to Japan and Taiwan. In US hospitals, temporary nurses, who are identified as 'agency nurses' or 'travel nurses' are popular, although most hired nurses in Japan and Taiwan are permanent staff.

Nurses who work fewer hours were more likely to rate patient safety condition of their work area as 'excellent' or 'very good'. Nurses who worked $<40$ h/week might be part-time workers who undertook uncomplicated tasks, whereas other nurses might have an increased chance not only to make but also to detect errors or near misses due to long working hours. The relationship between errors and long working hours has been reported previously $[10,11,14,15]$. Rogers et al. reported that nurses working $>12.5$-h shift or working for $\geq 12.5 \mathrm{~h}$ in a $24-\mathrm{h}$ period had 3.29 times increased likelihood of making an error (OR, 3.29, $\mathrm{p}=0.01$ ) compared with the 8.5-h shift group [11]. In contrast, the increased number of reports could be considered a sign of positive PSC under which the staff easily detected errors and felt free to report. In our study, long working hours were related to poor PSC and an increase in the number of adverse events 
Table 3 Mean scores of each sub-dimension in the different working hour groups

\begin{tabular}{|c|c|c|c|c|c|c|c|c|c|}
\hline \multirow[b]{3}{*}{ Sub-dimensions } & \multicolumn{3}{|c|}{ Japan } & \multicolumn{3}{|c|}{ U.S. } & \multicolumn{3}{|c|}{ Taiwan } \\
\hline & \multicolumn{3}{|c|}{$(n=4,047)$} & \multicolumn{3}{|c|}{$(n=106,710)$} & \multicolumn{3}{|c|}{$(n=5,714)$} \\
\hline & $\begin{array}{c}<40 \mathrm{~h} \\
(n=930)\end{array}$ & $\begin{array}{c}40-60 \mathrm{~h} \\
(n=2,352)\end{array}$ & $\begin{array}{c}\geq 60 \mathrm{~h} \\
(n=217)\end{array}$ & $\begin{array}{c}<40 \mathrm{~h} \\
(n=61,904)\end{array}$ & $\begin{array}{c}40-60 h \\
(n=35,488)\end{array}$ & $\begin{array}{c}\geq 60 \mathrm{~h} \\
(n=5,656)\end{array}$ & $\begin{array}{c}<40 \mathrm{~h} \\
(n=936)\end{array}$ & $\begin{array}{c}40-60 \mathrm{~h} \\
(n=4,226)\end{array}$ & $\begin{array}{c}\geq 60 \mathrm{~h} \\
(n=466)\end{array}$ \\
\hline Frequency of Event Reporting & 12.4 & 12.5 & 12.3 & 11.0 & 11.2 & 11.2 & 9.3 & 9.3 & 9.4 \\
\hline Overall Perceptions of Safety & 14.0 & 13.7 & 13.5 & 13.8 & 13.9 & 13.5 & 13.2 & 13.4 & 13.1 \\
\hline Supervisor/Manager Expectations \& Actions Promoting Safety & 15.0 & 14.8 & 14.8 & 15.2 & 15.3 & 14.9 & 14.4 & 14.7 & 14.2 \\
\hline Organizational Learning-Continuous Improvement & 10.7 & 10.6 & 10.6 & 11.2 & 11.3 & 11.2 & 11.6 & 11.7 & 11.5 \\
\hline Teamwork within Hospital Units & 15.3 & 15.1 & $14.6^{*}$ & 15.8 & 15.7 & 15.4 & 15.5 & 15.5 & $14.9^{*}$ \\
\hline Communication Openness & 10.6 & 10.5 & 10.4 & 10.9 & 11.0 & $10.7^{*}$ & 9.8 & 9.8 & $9.2^{*}$ \\
\hline Feedback and Communication about Error & 11. & 11.1 & 11.0 & 10.8 & 11.0 & 10.9 & 10.1 & 10.2 & 9.9 \\
\hline Nonpunitive Response-Error & 9.7 & 9.6 & 9.4 & 9.4 & 9.5 & 9.0 & 8.6 & 8.7 & $8.0^{*}$ \\
\hline Staffing & 12.2 & 11.8 & $10.9^{*}$ & 13.7 & 13.5 & $13.1^{*}$ & 12.0 & 11.9 & $10.6^{*}$ \\
\hline Hospital Management Support for Patient Safety & 10.4 & 10.3 & 10.2 & 10.7 & 10.8 & 10.6 & 10.6 & 10.6 & $10.2^{*}$ \\
\hline Teamwork Across Hospital Units & 13.2 & 13.0 & 12.9 & 13.4 & 13.3 & 13.2 & 13.6 & 13.7 & $13.1^{*}$ \\
\hline Hospital Handoffs \& Transitions & 12.7 & 12.5 & 12.2 & 12.8 & 12. & 12.2 & 12.8 & 12.7 & 12.3 \\
\hline
\end{tabular}

Each dimension is rated from 1-5 points and has three or four items resulting in a mean score of a dimension either from 3-15 points or 4-20 points; SD standard deviation ${ }^{*}$ Cohen's $d \geq 0.2$ and $P<0.05$, compared with the $<40$-h group. 
reported. An analysis adjusted for working hours or work stress might be needed to measure the relationship between a good PSC and the increase in the number of reported events.

In all the three countries, when nurses worked $\geq 60 \mathrm{~h} /$ week, the sub-dimension 'staffing' was rated poorer than those who worked $<40 \mathrm{~h} /$ week. Previous studies reported similar results, although they did not use HSOPS [16-20]. 'Nurse to patient ratio,' 'time of nursing care, 'nurse full time equivalents' and 'nurse whole time equivalents' were used as surrogate indicators of staffing. Long working hours might be related to poor staffing. If nurses needed to work $\geq 60 \mathrm{~h} /$ week, there might not be sufficient staff to handle the workload and they might be forced to work in a 'crisis mode'; trying to do too much too quickly.

In Japan and Taiwan, the situation of 'teamwork within units' in nurses working $<40 \mathrm{~h}$ /week was better than that of nurses working $\geq 60 \mathrm{~h} /$ week. Kalisch et al. in 2009 found that nurses working $<30 \mathrm{~h} /$ week rated their teamwork score significantly higher than those working $>30 \mathrm{~h} /$ week [21]. Other studies have reported that fatigue and stress scores in nurses who work a 12-h shift are significantly higher than those of nurses who work an 8-h shift $[22,23]$. Thus, increased fatigue, work intensity or work stress caused by long working hours might lead to mistakes or communication and interpersonal problems resulting in less teamwork without respect, understanding, support and helping one another [11,21-23]. Hospital managers may want to coordinate nurse working schedules to keep working hours appropriate to establish a good PSC. Such efforts might lead to a decrease in the number of adverse events due to miscommunication.

Although the two sub-dimensions of 'staffing' and 'teamwork within units' were related to working hours, the common deterioration patterns due to long working hours were not identified in the other 10 sub-dimensions. The difference in the deterioration pattern between countries might result from different mechanisms reflecting the cultural backgrounds.

This study had some limitations. It was unclear how the actual workload or work intensity affected PSC because objective indicators of 'staffing' such as patient-nurse ratio or patients' severity were not collected. Because of the sampling method in each country, the target population might not be representative of the entire country. The US response rate was lower than that of Japan and Taiwan, and the characteristics of non-respondents were unknown.

\section{Conclusions}

Patient safety grade deteriorated and the number of events reported increased with longer working hours among nurses in the three countries. Among 12 sub-dimensions of PSC, only the two sub-dimensions of 'staffing' and 'teamwork within units' were rated poorer in common when nurses worked long hours.

\section{Additional file}

Additional file 1: The difference among working hour groups by Tukey's test in Japan, the U.S. and Taiwan.

\section{Abbreviations}

HSOPS: Hospital survey on patient safety culture; PSC: Patient safety culture; AHRQ: Agency for healthcare research and quality; OR: Odds ratio; GLMM: Generalized linear mixed model.

\section{Competing interests}

The authors declare that they have no competing interests.

\section{Authors' contributions}

YW performed the statistical analysis and wrote the manuscript. SI and SF participated in the design of the study and performed the statistical analysis $\mathrm{CH}, \mathrm{KM}, \mathrm{KS}, \mathrm{SI}$ and SF collected the data and revised the manuscript. TH managed the entire research process. All authors read and approved the final manuscript.

\section{Acknowledgements}

The authors would like to thank the hospital staff who made this study possible by completing the questionnaires, and we also gratefully acknowledge the US $\mathrm{AHRQ}^{\dagger}$ for contributing to the study by offering us the US HSOPS data. This study was supported, in part, by the Grant-in-Aid for Exploratory Research (Grant No. 19659132) of the Japan Ministry of Education, Culture, Sports, Science and Technology. tUS data used in this analysis were from the Agency for Healthcare Research and Quality (AHRQ) Hospital Survey on Patient Safety Culture Comparative Database. The US database is funded by AHRQ and managed by Westat under contract \# HHSA 290200710024 C.

\section{Author details}

${ }^{1}$ Division of Health Policy \& Health Service Research, Department of Social Medicine, Toho University School of Medicine, 5-21-16 Omori-Nishi, Ota-ku, Tokyo 143-8540, Japan. ²Department of Senior Citizen Service Management, Ming-Hsin University of Science and Technology, Hsinchu, Taiwan.

Received: 8 March 2013 Accepted: 30 September 2013 Published: 7 October 2013

\section{References}

1. To Err is Human. In Building a Safer Health System. Edited by Kohn LT, Corrigan JM, Donaldson MS. Washington, DC: National Academies Press; 2000.

2. Leape LL: The preventability of medical injury. In Human Error in Medicine. Edited by Bogner MS. Hillsdale, NJ: Lawrence Erlbaum Associates; 1994:13-25.

3. Nieva VF, Sorra J: Safety culture assessment: a tool for improving patient safety in healthcare organizations. Qual Saf Health Care 2003, 12(Suppl 2):ii17-ii23.

4. Health and Safety Commission: Third Report: Organizing for Safety. ACSNI Study Group on Human Factors HMSO. London: ACSNI Study Group on Human Factors; 1993.

5. Agency for Healthcare Research and Quality: Hospital Survey on Patient Safety Culture. 2010. [http://www.ahrq.gov/qual/ patientsafetyculture/] (accessed 19 March 2013).

6. Sorra JS, Dyer N: Multilevel psychometric properties of the AHRQ hospital survey on patient safety culture. BMC Health Serv Res 2010, 10:199.

7. Ito S, Seto K, Kigawa M, Fujita S, Hasegawa T, Hasegawa T: Development and applicability of Hospital Survey on Patient Safety Culture (HSOPS) in Japan. BMC Health Serv Res 2011, 11:28.

8. Fujita $S$, Seto $K$, Ito $S$, Wu Y, Huang CC, Hasegawa T: The characteristics of patient safety culture in Japan, Taiwan and the United States. BMC Health Serv Res 2013, 13:20. 
9. Groves PS, Meisenbach RJ, Scott-Cawiezell J: Keeping patients safe in healthcare organizations: a structuration theory of safety culture. J Adv Nurs 2011, 67(8):1846-1855.

10. Scott $L D$, Rogers $A E$, Hwang WT, Zhang Y: Effects of critical care nurses' work hours on vigilance and patients' safety. Am J Crit Care 2006, 15(1):30-37.

11. Rogers AE, Hwang WT, Scott LD, Aiken LH, Dinges DF: The working hours of hospital staff nurses and patient safety. Health Aff (Millwood) 2004, 23(4):202-212.

12. Cohen J: A power primer. Psychol Bull 1992, 112:155-159.

13. Ministry of Education, Culture, Sports, Science and Technology: Ethical Guidelines for Epidemiological Research. http://www.lifescience.mext.go. jp/files/pdf/n796_01.pdf (accessed 19 March 2013).

14. Witkoski A, Dickson W: Hospital staff nurses' work hours, meal periods, and rest breaks. A review from an occupational health nurse perspective. AAOHN J 2010, 58(11):489-497.

15. Tabone $S$ : Data suggest nurse fatigue threatens patient safety. Tex Nurs 2004, 78(2):4-7.

16. Kane RL, Shamliyan T, Mueller C, Duval S, Wilt TJ: Nurse staffing and quality of patient care. Evid Rep Technol Assess (Full Rep) 2007, 151:1-115.

17. Numata $Y$, Schulzer $M$, van der Wal $R$, Globerman J, Semeniuk $P$, Balka E, Fitzgerald JM: Nurse staffing levels and hospital mortality in critical care settings: literature review and meta analysis. J Adv Nurs 2006, 55(4):435-448.

18. Lake $E T$, Friese $C R$ : Variations in nursing practice environments: relation to staffing and hospital characteristics. Nurs Res 2006, 55(1):1-9.

19. Lang TA, Hodge M, Olson V, Romano PS, Kravitz RL: Nurse-patient ratios: a systematic review on the effects of nurse staffing on patient, nurse employee, and hospital outcomes. J Nurs Adm 2004, 34(7-8):326-337.

20. Butler M, Collins R, Drennan J, Halligan P, O'Mathuna DP, Schultz TJ, Sheridan A, Vilis E: Hospital nurse staffing models and patient and staff-related outcomes. Cochrane Database Syst Rev 2011, 7, CD007019.

21. Kalisch BJ, Lee H: Nursing teamwork, staff characteristics, work schedules, and staffing. Health Care Manage Rev 2009, 34(4):323-333.

22. Yoder EA: Compassion fatigue in nurses. Appl Nurs Res 2010, 23:191-197.

23. Hoffman AJ, Scott LD: Role stress and career satisfaction among registered nurses by work shift patterns. J Nurs Adm 2003, 33(6):337-342.

\section{doi:10.1186/1472-6963-13-394}

Cite this article as: Wu et al:: The impact of nurse working hours on patient safety culture: a cross-national survey including Japan, the United States and Chinese Taiwan using the Hospital Survey on Patient Safety Culture. BMC Health Services Research 2013 13:394.

\section{Submit your next manuscript to BioMed Central and take full advantage of:}

- Convenient online submission

- Thorough peer review

- No space constraints or color figure charges

- Immediate publication on acceptance

- Inclusion in PubMed, CAS, Scopus and Google Scholar

- Research which is freely available for redistribution 